June 2005

\title{
Prevalence and predictors of smoking in Pakistan: results of the National Health Survey of Pakistan
}

\author{
Khabir Ahmed \\ Aga Khan University, khabir.ahmed@aku.edu \\ Fahim Jafary \\ Aga Khan University \\ Imtiaz Jehan \\ Aga Khan University \\ Juanita Hatcher \\ Tufts University Medical School, Boston, Massachusetts, USA \\ Abdul Qayum Khand, Khan \\ d Pakistan Medical Research Council, Pakistan, \\ See next page for additional authors
}

Follow this and additional works at: https://ecommons.aku.edu/pakistan_fhs_mc_surg_surg

Part of the Surgery Commons

\section{Recommended Citation}

Ahmed, K., Jafary, F., Jehan, I., Hatcher, J., Khan, A., Chaturvedi, N., Jafar, T. (2005). Prevalence and predictors of smoking in Pakistan: results of the National Health Survey of Pakistan. European Journal of Cardiovascular Prevention \& Rehabilitation, 12(3), 203-208.

Available at: https://ecommons.aku.edu/pakistan_fhs_mc_surg_surg/413 
Authors

Khabir Ahmed; Fahim Jafary; Imtiaz Jehan; Juanita Hatcher; Abdul Qayum Khand, Khan; Nish Chaturvedi; and Tazeen Jafar 


\section{Original Scientific Paper}

\section{Prevalence and predictors of smoking in Pakistan: results of the National Health Survey of Pakistan Khabir Ahmad ${ }^{a, b}$, Fahim Jafary ${ }^{c}$, Imtiaz Jehan ${ }^{a}$, Juanita Hatcher ${ }^{a}$, Abdul Qayum Khan ${ }^{\mathrm{d}}$, Nish Chaturvedi ${ }^{\mathrm{e}}$ and Tazeen H. Jafar ${ }^{\mathrm{a}, \mathrm{f}, \mathrm{g}}$}

${ }^{a}$ Clinical Epidemiology Unit, Department of Community Health Sciences, b Section of Ophthalmology, Department of Surgery, 'Section of Cardiology, Department of Medicine, Aga Khan University, Karachi, Pakistan, ${ }^{\mathrm{P}}$ Pakistan Medical Research Council, Islamabad, Pakistan, ${ }^{\mathrm{N}}$ National Heart and Lung Institute, Imperial College of Medicine at St. Mary's, UK, 'Section of Nephrology, Karachi, Pakistan and 'Division of Nephrology, Department of Medicine, Tufts-New England Medical Center, Tufts University Medical School, Boston, Massachusetts, USA.

Received 13 July 2004 Accepted 22 December 2004

Objective We analysed data collected during a nationwide cross-sectional household survey to estimate the prevalence of and identify factors associated with smoking in Pakistan.

Design Population-based, cross-sectional survey [National Health Survey of Pakistan (NHSP) 1990-1994].

Methods A population-based survey was carried out in Pakistan during 1990-1994. A nationally representative sample of 18135 individuals aged 6 months and older was surveyed. We restricted this analysis to individuals aged 15 years or older $(n=9442)$. The main outcome measure was self-reported smoking. Smokers were defined as individuals who reported current smoking and having smoked at least 100 cigarettes or 'beddies' during their lifetime.

Results Overall prevalence of smoking was 15.2\% [95\% confidence interval ( $\mathrm{Cl}), \mathbf{1 4 . 5 - 1 5 . 9 \%}$. It was 28.6\% (27.3-29.9\%) among men and $3.4 \%$ (2.9-3.9\%) among women. The highest prevalence was reported in men aged 40-49 years (40.9\%). The independent predictors of smoking identified in the multivariate logistic regression analysis included age, male gender, ethnicity and illiteracy.

Conclusions One out of every two to three middle-aged men in Pakistan smoke cigarettes. Our findings suggest that ethnically sensitive smoking control programmes that include measures for improving literacy rates are needed in Pakistan. Eur J Cardiovasc Prev Rehabil 12:203-208 (c) 2005 The European Society of Cardiology

European Journal of Cardiovascular Prevention and Rehabilitation 2005, 12:203-208

Keywords: prevalence of smoking, cross-sectional study, predictors of smoking, National Health Survey, Pakistan

\section{Introduction}

It is estimated that in the year 2000 alone, nearly half of the 4.83 million premature deaths attributable to smoking in the world occurred in developing countries, mainly among men aged $30-69$ years [1]. According to the World Health Organization, if appropriate preventive measures are not taken, the number of these deaths will increase to 10 million per year by 2030 , with $70 \%$ of them taking place in the developing world [2].

Correspondence and requests for reprints to Dr. Tazeen H. Jafar, Head, Section of Nephrology, Department of Medicine and Director, Clinical Epidemiology Unit, Department of Community Health Sciences, Aga Khan University, PO Box 3500, Stadium Road, Karachi, Pakistan.

Tel: + 92214930051 ext 4818; fax: + 92214934294 ;

e-mail: tazeen.jafar@aku.edu
South Asians, irrespective of where they live, have an increased risk of cardiovascular disease (CVD) in part because they have excess exposure to established CVD risk factors including diabetes, lack of aerobic exercise and low levels of high-density lipoprotein cholesterol [3-7]. Smoking further increases their risk of developing CVD. In many South Asian populations, smoking has become widespread, particularly among men, less educated individuals and the poor [8-10].

Recent published data showing a 20-year loss of life expectancy in a quarter of persistent smokers [11], adds to the call for the need to develop effective smoking control programmes in South Asian countries. However 
lack of nationally representative data in Pakistan on the burden and determinants of smoking hampers the development of a relevant and evidence-based smoking control programme. Those few studies that have looked at the prevalence of smoking have been conducted in localized geographical areas [12-17].

The National Health Survey of Pakistan (NHSP) 19901994 was the first nationally representative study to collect data on smoking in Pakistan [18]. Although the prevalence of smoking among the Pakistani population has been reported previously [19], independent determinants of smoking have not been studied. We analysed the NHSP data to estimate the prevalence of and identify factors associated with smoking among individuals aged 15 years or older.

\section{Methods}

The present analysis is based on data collected during a cross-sectional nationwide household survey. The NHSP was commissioned by the Pakistan Medical Research Council (PMRC) between 1990 and 1994, and designed and conducted under the technical assistance of the United States National Centre for Health Statistics. The survey was administered to a nationally representative sample ( $n=18135$ individuals aged 6 months and older) belonging to 2400 households. This analysis was restricted to individuals aged 15 years or older $(n=9442)$. The design of the survey was a modification of United States' Third National Health and Nutrition Examination Survey (NHANES III). The details of methodology used in the NHSP have been reported previously [19-21]. In summary, the survey used a two-stage stratified design, taking urban and rural areas of each of the four provinces of Pakistan as strata. The country was divided into 80 urban and rural primary sampling units. Thirty households were selected randomly from each unit, and all members of the household aged at least 6 months were surveyed. The overall individual response rate was $92.6 \%$. Data collection involved the use of a questionnaire, which had been validated in local languages. Data were collected on variables including demographic, socioeconomic, and lifestyle factors. All respondents underwent a standardized physical examination by physicians. Technicians performed anthropometric examinations.

Respondents were asked, 'Have you smoked at least 100 cigarettes or 'beddies' during your entire life?' Those who replied 'yes' were asked, 'Do you smoke now?' Current smokers were persons who reported current smoking and having smoked at least 100 cigarettes or 'beddies' during their lifetime. Respondents were also asked, 'Have you chewed tobacco or used snuff at least 100 times during your entire life?' Those who said 'yes' were asked, 'Do you chew tobacco or use snuff now?' Those respondents who replied they did were reported as current tobacco chewers/snuff users.

Our definition of ethnicity was based on the mother tongue of the respondents, which is specific for each of the five major ethnic groups in Pakistan: Punjabi, Pushtun, Muhajir, Sindhi, and Baluchi. As reported previously $[20,22]$, these groups have distinct places of origin, cultural practices and values, health beliefs, and behaviours. Furthermore, almost two-thirds of marriages in Pakistan are consanguineous, resulting in relative homogeneity within ethnic groups. Respondent's socio-economic status (SES) was defined through a count of a number of items they owned. This measure has been validated previously [23]. Literacy was defined as ability to read.

\section{Statistical analysis}

We used SAS version 8.0 (SAS Institute Inc., Cary, North Carolina, USA) for analysis. Means and standard deviations were computed for continuous while proportions and $95 \%$ confidence intervals (CI) for categorical study variables. The final analysis was restricted to individuals aged 15 and above belonging to one of the five major ethnic groups. Thus, the final sample size for the multivariable model was 8328 . The association between smoking and potential predictors such as age, sex, literacy status and SES was investigated, using univariate logistic regression. Variables that were associated with smoking at $P$-value $<0.2$ in the univariate analysis or were biologically important were considered for multivariate logistic regression analysis. Factors that were included in the final model were age, ethnicity, sex, literacy, urban/rural dwelling. Although socio-economic status was not significantly associated with smoking, it was retained in the final model.

\section{Results}

Of the 9442 individuals who were 15 years of age and older, $15.2 \%$ (95\% CI, 14.5-15.9\%) smoked (Table 1). In addition, $10.7 \%$ (95\% CI, 10.1-11.3\%) chewed tobacco or used snuff. The overall prevalence (95\% CI) of smoking was more than eight-fold higher among men $(28.6 \%$ [27.3-29.9]) than among women (3.4\% [2.9-3.9]) (Table 2). Men aged 40-49 years had the highest prevalence of smoking: $40.9 \%$ (36.9-44.9).

In the univariate analysis, statistically significant associations $(P$-value $<0.2)$ were found between smoking and age, gender, place of dwelling (urban/rural), socioeconomic status, and literacy status. In the multivariate analysis, men were more likely to be smokers as compared to women [adjusted odds ratio $(\mathrm{OR})=14.64(95 \% \mathrm{CI}$ : 12.13-17.67)]. As compared with those aged less than 20 years, subjects aged 20-39 years (adjusted $O R=5.57$; 95\% CI: $4.22-7.35$ ) and $40-59$ years (adjusted OR $=6.59$; 95\% CI: 4.93-8.81) were more likely to be current 
smokers. In addition, the odds of smoking among the Sindhis were 1.34 times the odds of smoking among the Punjabis. The odds of smoking were lower among Muhajirs (adjusted OR $=0.61 ; 95 \%$ CI: $0.50-0.73$ ) and the Pashtuns (adjusted OR $=0.28$; 95\% CI: $0.21-0.37$ ) as compared to the Punjabis. Urban dwelling (adjusted $\mathrm{OR}=1.43 ; 95 \%$ CI: $1.23-1.67$ ) and literacy (adjusted $\mathrm{OR}=0.69 ; 95 \%$ CI: $0.59-0.80)$ were also important independent predictors of smoking (Table 3).

\section{Discussion}

Our analysis provides the first nationally representative estimate of the prevalence of smoking amongst people

\begin{tabular}{|c|c|}
\hline Characteristics & $\%(95 \% \mathrm{Cl}) *$ \\
\hline Current cigarette smokers & $15.2(14.5-15.9)$ \\
\hline Currently chew tobacco/snuff only & $10.7(10.1-11.3)$ \\
\hline $\begin{array}{l}\text { Currently chew tobacco or smoke } \\
\text { cigarette }\end{array}$ & $24.5(23.6-25.4)$ \\
\hline Age (SD) & $36.3(17.1)$ \\
\hline Male & $46.7(45.2-48.2)$ \\
\hline${ }^{\ddagger}$ High SES & $17.9(17.1-18.7)$ \\
\hline Middle SES & $49.0(47.9-50.0)$ \\
\hline Low SES & $33.1(32.1-34.0)$ \\
\hline \multicolumn{2}{|l|}{ Height in $\mathrm{cms}$} \\
\hline Male (SD) & $167.2(8.0)$ \\
\hline Female (SD) & $154.2(6.8)$ \\
\hline \multicolumn{2}{|l|}{ Weight in kgs } \\
\hline Male (SD) & $57.6(11.3)$ \\
\hline Female (SD) & $50.6(11.3)$ \\
\hline \multicolumn{2}{|l|}{ Body-mass index $(\mathrm{BMI})$ in $\mathrm{kg} / \mathrm{m}^{2}$} \\
\hline Male (SD) & $20.9(4.6)$ \\
\hline Female (SD) & $21.7(5.6)$ \\
\hline \multicolumn{2}{|l|}{ Urban dwellers } \\
\hline Male & $36.4(35.0-37.8)$ \\
\hline Female & $35.5(34.2-36.8)$ \\
\hline \multicolumn{2}{|l|}{$\S$ Literate } \\
\hline Male & $46.9(45.4-48.4)$ \\
\hline Female & $18.9(17.8-19.9)$ \\
\hline \multicolumn{2}{|l|}{ Waist-hip ratio } \\
\hline Male (SD) & $0.88(0.1)$ \\
\hline Female (SD) & $0.89(0.1)$ \\
\hline \multicolumn{2}{|l|}{${ }^{\infty}$ Overweight/obesity } \\
\hline Male & $13.5(12.5-14.5)$ \\
\hline Female & $19.6(18.5-20.7)$ \\
\hline
\end{tabular}

*Values given as \% [95\% confidence interval (Cl)] unless otherwise indicated. ${ }^{\ddagger}$ Socio-economic status: three levels of economic status were defined through a simple count of the number of items owned. \$Literacy was defined as ability to read. ${ }^{\infty}$ Overweight/obesity was defined as BMI greater than $25 \mathrm{~kg} / \mathrm{m}^{2}$. aged 15 years or older in Pakistan. The overall prevalence of smoking among individuals aged 15 years or older was $15.2 \%$, which is comparable to that $(15.8 \%)$ observed in a similar study in neighbouring India [10].

In our study, gender was the strongest predictor of smoking: the prevalence of smoking was $28.6 \%$ in men versus $3.4 \%$ in women $(P<0.001)$. This finding is consistent with those of several regional studies. In a study conducted in the Ghizar district in northern Pakistan, the prevalence of current smoking was $43.7 \%$ among men and 5.5\% among women (aged 18 years and older) [16]. These disparities in smoking prevalence by gender have also been consistent with data from India and Indonesia [24,25]. For example, in urban Delhi, 45\% men versus $7 \%$ women smoked [25]. There are several factors that may explain gender-specific differences in our study. First, many women might have concealed their smoking status from the interviewers for socio-cultural reasons. Second, smoking by women is not perceived as socially acceptable in Pakistan and as a result far fewer women smoke [26]. Because of their historically lower smoking rates, women in developing countries remain a key target of the tobacco industry. Efforts to target women in developed countries have already been rewarded because there is more smoking among teenage girls than boys in several developed countries [27]. It is feared that girls in the developing countries may follow the same trends [27]. Therefore, concrete efforts are needed to protect them from the effects of aggressive marketing policies adopted by multinational and national tobacco companies.

Our analysis also showed that smoking rates were very high among men of the most productive age group (20-59 years). Of Pakistan's 133.6 million population, 54.3 million people (27.4 million men and 26.9 million women) are in this age group. We estimated that 10.6 million people in this age group (9.6 million men and 1 million women) were current smokers. A very high prevalence in this age group particularly among men could result in enormous productivity losses in the country, and calls for immediate targeted smoking cessation programs.

Table 2 Age specific prevalence of cigarette smoking in Pakistan as assessed in the National Health Survey of Pakistan ( $n=9442)$

\begin{tabular}{|c|c|c|c|c|c|c|}
\hline \multirow[b]{2}{*}{$\begin{array}{c}\text { Age group } \\
\text { (years) }\end{array}$} & \multicolumn{2}{|c|}{ All } & \multicolumn{2}{|c|}{ Men } & \multicolumn{2}{|c|}{ Women } \\
\hline & Number of subjects & $\begin{array}{c}\text { Prevalence of smoking } \\
\qquad(95 \% \mathrm{Cl})\end{array}$ & Number of subjects & $\begin{array}{l}\text { Prevalence of smoking } \\
\qquad(95 \% \mathrm{Cl})\end{array}$ & Number of subjects & $\begin{array}{c}\text { Prevalence of smoking } \\
\qquad(95 \% \mathrm{Cl})\end{array}$ \\
\hline $15-19$ & 1646 & $4.4(3.4-5.4)$ & 797 & $8.3(6.4-10.2)$ & 849 & $0.7(0.1-1.3)$ \\
\hline $20-29$ & 2411 & $14.4(13.0-15.8)$ & 1050 & $30.1(27.3-32.9)$ & 1361 & $2.1(1.3-2.9)$ \\
\hline $30-39$ & 1849 & $20.3(18.5-22.1)$ & 830 & $39.9(36.6-43.2)$ & 1019 & $4.3(3.1-5.5)$ \\
\hline $40-49$ & 1311 & $21.4(19.2-23.6)$ & 587 & $40.9(36.9-44.9)$ & 724 & $5.7(4.0-7.4)$ \\
\hline $50-59$ & 971 & $17.9(15.5-20.3)$ & 481 & $31.8(27.6-36.0)$ & 490 & $4.3(2.5-6.1)$ \\
\hline$\geq 60$ & 1254 & $14.5(12.6-16.4)$ & 669 & $32.7(29.1-36.3)$ & 585 & $5.1(3.3-6.9)$ \\
\hline Total & 9442 & $15.2(14.5-15.9)$ & 4414 & $28.6(27.3-29.9)$ & 5028 & $3.4(2.9-3.9)$ \\
\hline
\end{tabular}

$\mathrm{Cl}$, confidence interval. 
Table 3 Unadjusted and adjusted odds ratio for cigarette smokers for adults aged 15 years and above and belonging to one of the five major ethnic groups $(n=8328)$

\begin{tabular}{|c|c|c|c|c|}
\hline Characteristics & All & Smokers (\%) & $\begin{array}{l}\text { Unadjusted odds ratio for cigarette } \\
\text { smoking }(95 \% \mathrm{Cl})\end{array}$ & $\begin{array}{l}\text { *Adjusted odds ratio for cigarette smoking } \\
\qquad(95 \% \mathrm{Cl})\end{array}$ \\
\hline Number of individuals & 8328 & $1280(15.3)$ & & \\
\hline \multicolumn{5}{|l|}{ Age groups in years } \\
\hline$<20$ & 1485 & $63(4.9)$ & 1.00 & 1.00 \\
\hline $20-39$ & 3757 & $641(50.1)$ & $4.63(3.55-6.04)$ & $5.57(4.22-7.35)$ \\
\hline $40-59$ & 1991 & 408 (31.9) & $5.80(4.41-7.63)$ & $6.59(4.93-8.81)$ \\
\hline$\geq 60$ & 1095 & $168(13.1)$ & $4.08(3.02-5.51)$ & $3.45(2.50-4.76)$ \\
\hline \multicolumn{5}{|l|}{ Ethnicity (\%) } \\
\hline Punjabi & 3698 & $655(51.1)$ & 1.00 & 1.00 \\
\hline Muhajir & 1673 & $219(17.1)$ & $0.70(0.59-0.83)$ & $0.61(0.50-0.73)$ \\
\hline Baluchi & 295 & $53(4.1)$ & $1.02(0.75-1.39)$ & $0.74(0.53-1.04)$ \\
\hline Sindhi & 1520 & $285(22.3)$ & $1.07(0.92-1.25)$ & $1.34(1.12-1.59)$ \\
\hline Pushtun & 1142 & $68(5.3)$ & $0.29(0.23-0.38)$ & $0.28(0.21-0.37)$ \\
\hline Male (\%) & 3579 & $1128(88.1)$ & $11.2(9.39-13.4)$ & $14.64(12.13-17.67)$ \\
\hline Urban dwellers (\%) & 3208 & $533(41.6)$ & $1.17(1.03-1.32)$ & $1.43(1.23-1.67)$ \\
\hline Literate (\%) & 2861 & $491(38.4)$ & $1.23(1.09-1.39)$ & $0.69(0.59-0.80)$ \\
\hline \multicolumn{5}{|c|}{ Socio-economic status (SES) } \\
\hline Low SES & 2523 & $420(32.8)$ & 1.00 & 1.00 \\
\hline Middle SES & 4199 & $640(50)$ & $0.90(0.79-1.03)$ & $1.03(0.88-1.20)$ \\
\hline High SES & 1606 & $220(17.1)$ & $0.80(0.67-0.95)$ & $1.13(0.92-1.39)$ \\
\hline
\end{tabular}

*Adjusted odds ratios for smoking cigarette are based on the multivariable model. This analysis was restricted to individuals aged 15 and above belonging to one of the five major ethnic groups $(n=8328)$. $\mathrm{Cl}$, confidence interval.

The prevalence of smoking increased abruptly at younger ages with rates of $8.3 \%(6.4-10.2 \%)$ in men jumping to $30.1 \%(27.3-32.9 \%)$ in those aged $20-29$ years. It is quite possible that the relatively lower rate of smoking in teenagers is due to under-reporting. Data from the United States indicate that a significant increase in smoking rates has occurred among persons aged 18-24 years over the past few years [28]. Data from developing countries also indicate that teenage smoking is a growing problem [10,29-31]. Thus, it is extremely important to target this vulnerable segment of the population in smoking cessation programmes.

An important finding of our analysis was the lower smoking rates among men aged 50 years or older. Although it is possible that men in this group are giving up smoking or never taking it up, one possible explanation is that many of smokers could be dying of smokingrelated illnesses. Similar lower rates have also been reported in India [10]. A large study indicated recently that among males in India, smoking is associated with a quarter of all deaths in middle age (with a loss of 20 years of life expectancy). Further, a third of the deaths caused by smoking are from vascular disease [11]. The relatively early age of CVD and CVD-related deaths among South Asians compared with other ethnic groups is well documented [32,33]. For example in India nearly half of CVD-related deaths occur below the age of 70 years as compared to developed countries where only one in five of these deaths occur below the age of 70 years [34]. In a case-control study, we recently found that current smoking was associated with a very high risk of acute myocardial infarction (AMI) in young South Asians [35]. Further research is needed to investigate the causes of relatively lower rates of smoking in individuals aged 50 years and above.

The association between ethnicity and smoking has been reported widely [36,37]. For example in the UK, men of South Asian origin had a higher prevalence of smoking than men in the general population. However, South Asian women had a lower prevalence of smoking than women in the general population [37]. Our analysis showed that the prevalence of smoking varied widely among the five major ethnic groups in Pakistan. Smoking rates were higher among the Sindhis than the Punjabis. As compared with the Punjabis, the odds of smoking were lower among the Muhajirs and the Pashtuns. However, both these groups, particularly the Pashtuns had a very high prevalence of snuff/chewable tobacco use. Our analysis showed that $20.5 \%$ of Pashtuns chewed tobacco or used snuff (data not shown). The use of snuff (naswar) is particularly common in Pakistan's Pushtun-populated areas because they are the leading growers of tobacco. Like chewing tobacco, naswar is made locally in small shops. It is far cheaper than cigarette and readily available even in remote villages. Similarly, tobacco chewing is particularly common in Pakistan's Muhajirs (11.8\%) because it may well be that they brought with them this habit from India where tobacco chewing is a public health problem. Around $20 \%$ people currently chew tobacco in India [10]. A sound understanding of ethnic differences in smoking rates is necessary because it helps provide information needed to develop appropriate tobacco control programmes. Based on our findings, we recommend ethnically sensitive tobacco control policies in Pakistan focusing more on chewable tobacco in the Pashtuns. 
Our results also indicated an independent association between place of dwelling and current smoking. Individuals living in urban areas were more likely to be smokers as compared with rural-dwellers (adjusted $\mathrm{OR}=1.43$; 95\% CI: $1.23-1.67)$.

It is interesting to note that in the univariate analysis literacy was associated with smoking $(\mathrm{OR}=1.23,95 \% \mathrm{CI}$ : 1.09-1.39). However, this relationship reversed in the bivariate analysis after adjusting for male gender $(\mathrm{OR}=0.64 ; 95 \%$ CI: $0.56-0.73)$ suggesting that the apparently higher rates of smoking in literate versus illiterate respondents were confounded by a greater proportion of men as compared to women in the latter. The multivariate analyses confirmed that literate respondents were less likely (adjusted OR $=0.69$; 95\% CI: 0.59 $0.80)$ to be current smokers as compared with their illiterate counterparts. It is likely that literate people were more aware of the health hazards of smoking as compared with their illiterate counterparts. Various studies have suggested that uneducated people are more likely to smoke than their educated counterparts $[10,25]$. Although the dichotomy of literacy status into literate and illiterate limits its comparability with other studies, our study has major implications for smoking control policy in Pakistan because the majority of adults aged 15 and over (43.6 million of 76.5 million) in the country are illiterate (unable to read). Therefore, public policy for prevention of smoking must also prioritize measures for improving literacy rates in Pakistan, and ensure that messages are available for illiterate people.

Our analysis had the following limitation. The definition of smoking is based on self-reported smoking and not on serum cotinine levels, which are a better measure of smoking status. However, a good agreement occurs between self-reported smoking status and high serum cotinine levels [37].

\section{Conclusions}

Our analysis of a large nationally representative data provides important information on the prevalence and determinants of smoking in Pakistan and could pave the way for the development of a smoking control programme in the country. One out of every two to three middle-aged men smoke cigarettes in Pakistan. Our findings suggest that ethnically sensitive smoking control programmes that include measures for improving literacy rates are needed in Pakistan.

\section{Acknowledgements}

We thank members of the Pakistan Medical Research Council, and the United States Department of Health and Human Services for their assistance in acquisition of the NHSP data. This research was supported by grants from Fogarty International Centre, NIH (T.H.J and N.C).

\section{References}

1 Ezzati M, Lopez AD. Estimates of global mortality attributable to smoking in 2000. Lancet 2003; 362:847-852.

2 WHO Framework Convention on Tobacco Control. Tobacco fact sheet. 11th Conference on Tobacco OR Health. World Health Organization, 2000.

3 Wilkinson P, Sayer J, Koorithottumaki L, Grundy C, Bradely M, Kopelman P, et al. Comparison of case fatality in south Asian and white patients after acute myocardial infarction: observational study. BMJ 1996; 312: 1330-1333.

4 UK Prospective Diabetes Study Group: ethnicity and cardiovascular disease. The incidence of myocardial infarction in white, South Asian, and Afro-Caribbean patients with type II diabetes. Diabetes Care 1998; 21:1271-1277.

5 Anand SS, Yusuf S, Vuksan V, Devanesen D, Teo KK, Montague PA, et al. Differences in risk factors, atherosclerosis, and cardiovascular disease between ethnic groups in Canada: the Study of Health Assessment and Risk in Ethnic groups (SHARE). Lancet 2000; 356:279-284.

6 Pais P, Pogue J, Gerstein H, Zachariah E, Savitha D, Jayprakash S, et al. Risk factors for acute myocardial infarction in Indians: a case-control study. Lancet 1996; 348:358-363.

7 Pais P, Fay MP, Yusuf S. Increased risk of acute myocardial infarction associated with beedi and cigarette smoking in Indians: final report on tobacco risks from a case-control study. Indian Heart J 2001; 53: 731-735.

8 Gajalakshmi VPR. Tobacco epidemiology in the state of Tamil Nadu, India. Asian Pac J Cancer Prev 2000; 1:199-201.

9 Cohen N. Smoking, health, and survival: prospects in Bangladesh. Lancet 1981; 1:1090-1093.

10 Rani M, Bonu S, Jha P, Nguyen SN, Jamjoum L. Tobacco use in India: prevalence and predictors of smoking and chewing in a national cross sectional household survey. Tob Control 2003; 12:E4.

11 Gajalakshmi V, Peto R, Kanaka TS, Jha P. Smoking and mortality from tuberculosis and other diseases in India: retrospective study of 43,000 adult male deaths and 35,000 controls. Lancet 2003; 362:507-515.

12 Jaleel MA, Nooreen R, Parveen A, Farhana, Nadeem, Hameed A. Comparison of population survey of Multan about cigarette smoking with survey of Abbottabad. J Ayub Med Coll Abbottabad 2002; 14: 16-19.

13 Jaleel MA, Noreen R, Hameed A, Hussain A, Rauf S, Ali L, et al. An epidemiological study of smoking at Abbottabad. J Ayub Med Coll Abbottabad 2001; 13:34-36.

14 Maher R, Devji S. Prevalence of smoking among Karachi population. J Pak Med Assoc 2002; 52:250-253.

15 Merchant AT, Luby SP, Perveen G. Smoking among males in a low socioeconomic area of Karachi. J Pak Med Assoc 1998; 48:62-63.

16 Shah SM, Arif AA, Delclos GL, Khan AR, Khan A. Prevalence and correlates of smoking on the roof of the world. Tob Control 2001; 10:42.

17 Rozi S, Akhtar S. Smoking among high school adolescents in Karachi, Pakistan. Int J Epidemiol 2004; 33:1.

18 National Health Survey of Pakistan 1990-1994: Pakistan Medical Research Council, 1998.

19 Nasir K, Rehan N. Epidemiology of cigarette smoking in Pakistan. Addiction 2001; 96:1847-1854.

20 Jafar TH, Chaturvedi N, Gul A, Khan AQ, Schmid CH, Levey AS. Ethnic differences and determinants of proteinuria among South Asian subgroups in Pakistan. Kidney Int 2003; 64:1437-1444.

21 Mallick M. Sample design for the National Health Survey of Pakistan. Pak J Med Res 1992; 31:289-290.

22 Jafar TH, Levey AS, Jafary FH, White F, Gul A, Rahbar MH, et al. Ethnic subgroup differences in hypertension in Pakistan. $J$ Hypertens 2003; 21:905-912.

23 Midhet FKM, Berendes H. Situation of Women and Children's Health in Rural Areas of North-West Frontier Province and FATA, Pakistan: National Institute of Child Health and Human Development, Bethesda, and Department of Community Health Sciences. The Aga Khan University, Karachi, 1997.

24 Barraclough S. Women and tobacco in Indonesia. Tob Control 1999; 8:327-332.

25 Narayan KM, Chadha SL, Hanson RL, Tandon R, Shekhawat S, Fernandes $\mathrm{RJ}$, et al. Prevalence and patterns of smoking in Delhi: cross sectional study. BMJ 1996; 312:1576-1579.

26 Bush J, White M, Kai J, Rankin J, Bhopal R. Understanding influences on smoking in Bangladeshi and Pakistani adults: community based, qualitative study. BMJ 2003; 326:962.

27 World Bank. Curbing the epidemic: governments and the economics of tobacco control. Washington DC: World Bank; 1999. 
28 Cigarette smoking among adults-United States, 1998. MMRW 2000; 49:881-884.

29 Smet B, Maes L, De Clercq L, Haryanti K, Winarno RD. Determinants of smoking behaviour among adolescents in Semarang, Indonesia. Tob Control 1999; 8:186-191.

30 Sinha DN, Gupta PC, Pednekar MS. Tobacco use among students in the eight Northeastern states of India. Indian J Cancer 2003; 40:43-59.

31 Ahsan H, Underwood P, Atkinson D. Smoking among male teenagers in Dhaka, Bangladesh. Prev Med 1998; 27:70-76.

32 Balarajan R. Ethnic differences in mortality from ischaemic heart disease and cerebrovascular disease in England and Wales. BMJ 1991; 302: 560-564.
33 McKeigue PM, Ferrie JE, Pierpoint T, Marmot MG. Association of early-onset coronary heart disease in South Asian men with glucose intolerance and hyperinsulinemia. Circulation 1993; 87:152-161.

34 World Health Organization. World Health Report 2003. Shaping the future. Geneva: World Health Organization; 2003.

35 Ismail J, Jafar TH, Jafary FH, White F, Faruqui AM, Chaturvedi N. Risk factors for non-fatal myocardial infarction in young South Asian adults. Heart 2004; 90:259-263.

36 Cigarette smoking among adults-United States, 2001. MMRW 2003; 52:953-956.

37 Department of Health. Health survey for England. London: Stationery Office; 1999. 